\title{
POTENTIAL OF HIGH-RESOLUTION SATELLITE IMAGERY FOR MAPPING DISTRIBUTION AND EVALUATING ECOLOGICAL CHARACTERISTICS OF TREE SPECIES AT THE ANGKOR MONUMENT, CAMBODIA
}

\author{
MIZUKI TOMITA ${ }^{1}$, YOSHIHIKO HIRABUKI ${ }^{2}$, YUJI ARAKI ${ }^{3}$, SHINJI TSUKAWAKI $^{4}$, \\ BORA LY ${ }^{5}$ AND PEOU HANG ${ }^{5}$
}

\begin{abstract}
${ }^{1}$ Faculty of Informatics, Tokyo University of Information Sciences, Onaridai 4-1, Wakaba-ku, Chiba 265-8501, Japan; e-mail,tomita@rsch.tuis.ac.jp;

${ }^{2}$ Faculty of Liberal Arts, Tohoku Gakuin University, Tenjinzawa 2-1-1, Izumi-Ku, Sendai 981-3193, Japan;

${ }^{3}$ Faculty of Education, Saitama University, Shimo-Okubo, Sakura-ku, Saitama 338-8507, Japan;

${ }^{4}$ Institute of Nature and Environmental Technology, Kanazawa University, Kakuma-machi, Kanazawa, Ishikawa 920-1192, Japan;

${ }^{5}$ Authority for Protection and Management of Angkor and the Region of Siem Reap, Bangkoung Village, Ampil District, Siem Reap Town, Siem Reap Province, Cambodia
\end{abstract}

Received: $5^{\text {th }}$ April 2010, Accepted: $5^{\text {th }}$ November 2014

\section{AbSTraCT}

Large trees play several vital roles in the Angkor monuments landscape. They protect biodiversity, enhance the tourism experience, and provide various ecosystem services to local residents. A clear understanding of forest composition and distribution of individual species, as well as timely monitoring of changes, is necessary for conservation of these trees. Using traditional field work, obtaining this sort of data is time-consuming and labour-intensive. This research investigates classification of very high resolution remote sensing data as a tool for efficient analyses. QuickBird satellite imagery was used to clarify the tree species community in and around Preah Khan temple, to elucidate differences in ecological traits among the three dominant species (Dipterocarpus alatus, Lagerstroemia calyculata and Tetrameles nudiflora), and to identify crowns of the dominant species.

Population structures of trees were determined using a 14.26ha study plot. Species name, $\mathrm{DBH}$, height, height under the crown and crown area were recorded for all trees over $40 \mathrm{~cm}$ in DBH. Tree locations were also recorded so as to provide references for the imagery analysis. Ecological traits of the dominant species were estimated using regressions by an expanded allometric equation for both large and small trees, based on $\mathrm{DBH}$, height, height under the crown and crown width.

The total number of species in the study plot was 45 . From a spatial perspective, the three dominant species over $100 \mathrm{~cm}$ in $\mathrm{DBH}$ were segregated from each other. D. alatus, L. calyculata and T. nudiflora were concentrated, respectively, along the approach to the temple, near the centre of the complex, and on the walls of the monument. Object Based Image Analysis (OBIA) conducted using QuickBird satellite imagery, showed that crowns of D. alatus were largely determined by maximum of NIR layer and mean of digital number in 
Tomita M., Hirabuki Y., Araki Y., Tsukawaki S., Ly B. \& Hang P.: Potential of high-resolution satellite imagery for mapping distribution and evaluating ecological characteristics of tree species at the Angkor monument, Cambodia

panchromatic layer. Differences in the parameters for both asymptotic height and spatial distribution among the dominant species, result from differences in ecological traits, and enhance the value of the tourism resource by providing a dramatic shift of forest scenery that can be enjoyed by visitors to the monument.

Key words: allometric relationships, object based image analysis, QuickBird imagery, spatial distribution, tree community

\section{INTRODUCTION}

Tropical and subtropical tree communities, particularly those including huge emergent trees, provide superb forest scenery for tourists, not only in old-growth forest, but also in forest remaining near rural areas. In the Angkor monuments region, huge tree species belonging to the families Dipterocarpaceae, Lythraceae and Datiscaceae provide spectacular scenery, and also help ameliorate physical degradation of the monuments. Recently, environmental problems such as illegal logging and atmospheric and groundwater pollution have increased, along with development of the tourism industry in Siem Reap. The huge remnant trees are thus important for conservation of both biodiversity and tourism resources. Protection of these trees requires an understanding of their ecological traits, and of their contributions in conserving the Angkor monuments landscape.

Field research on trees and forests is time-consuming, labour-intensive and requires special skills and training. In recent years, however, new technologies employing Geographic Information Systems (GIS) and remote sensing technology are being examined as tools for efficient identification of tree species, vegetation/tree mapping and classification of land-use (e.g. Alexander \& Millington, 2000; Palace et al., 2008; Katoh et al., 2009; Hirata et al. 2009; Zhao et al., 2014). In particular, remote sensing using very high resolution data, such as QuickBird, offers the potential for streamlining the process of producing maps of individual trees. In the last three decades, advances in computer technology, earth observation sensors and GIS science has led to the development of "Object-based image analysis (OBIA)" as an alternative to the traditional pixel-based image analysis (Baatz \& Schape, 2000; Blaschke \& Strobl, 2001; Blaschke, 2010). OBIA works on objects which are produced by image segmentation. As an object is a group of pixels, characteristics such as the mean and standard deviation of spectral values can be calculated and used in the classification. Grouping pixels is an effective method for overcoming the so called 'salt and pepper effect (Blaschke et al., 2000) that often plagues pixel based classifications; and many researchers now prefer OBIA to traditional pixel-based image analysis (Blaschke, 2010). This OBIA method, if able to extract canopies and identify tree species, would be an extremely useful and laborsaving tool for management of tree communities in and around the Angkor monuments region.

The objectives of the present study were: (1) to clarify the current status of the tree species and tree communities in the Preah Khan monumental complex, (2) to detect differences in allometric relationships between diameter and height and/or crown width, among the top three dominant species (Dipterocarpus alatus, Lagerstroemia calyculata and Tetrameles nudiflora), (3) to detect crowns of the dominant tree species in and around the temple using QuickBird satellite imagery, and (4) to evaluate the bands most effective for detecting crowns and identifying tree species. This study is still in the preliminary stages, particularly in regards to detection and classification of crowns and species. 


\section{METHODS}

The Preah Khan temple, being one of the few monumental complexes at Angkor still surrounded by forests, was selected as the research site. Preah Khan is situated in the northern part of Angkor, Siem Reap, Cambodia (13 $27^{\circ} \mathrm{N}, 103^{\circ} 52^{\prime} \mathrm{E}$; ca. 56ha). The central sanctuary of Preah Khan was built in 1191 and prospered as a monastery and teaching complex. Like many of the other historical sites, Preah Khan was rediscovered in the late $19^{\text {th }}$ Century. A protected forest surrounds the outer moat. This forest (ca. 150 ha) plays several important roles; (1) as a remnant of the Dipterocarpaceae-dominant seasonal-dry forest, (2) as a vital tourism resource and (3) as a developed ecosystem providing various services to the local people.

Population structures and spatial distributions of remnant trees were determined using a 14.26ha study plot. The scientific and local names, diameter at breast height (DBH), height $(\mathrm{H})$, height under the crown, and crown area were recorded for all trees over $40 \mathrm{~cm}$ in DBH. This field research was conducted in March in 2008 and 2009, with the assistance of the Authority for Protection and Management of Angkor and the Region of Siem Reap (APSARA) staff. The number of other tree canopies (OTC) over each target tree was also recorded. An OTC value of zero indicates that the canopy of the target tree was exposed to the sky.

To provide references for detection of the dominant tree species using ArcGIS, all the tree location and crown data were overlaid onto a QuickBird satellite image (copyright, Digital Globe Inc.), which was acquired over the study area (during a period without clouds) in January 2004. The January 2004 image was selected because there was no suitable image available from 2005 to 2009 . The QuickBird dataset consisted of single band panchromatic imagery $(450-900 \mathrm{~nm})$ with spatial resolution of $0.61 \times 0.61 \mathrm{~m}$, and four band multispectral imagery (blue: 450 - $520 \mathrm{~nm}$, green:520 - $600 \mathrm{~nm}$, red:630 - $690 \mathrm{~nm}$ and NIR:760 - $900 \mathrm{~nm}$ ) with spatial resolution of $2.4 \times 2.4 \mathrm{~m}$.

To describe differences in ecological traits of the top three dominant tree species, height (or crown width) and diameter relationships were regressed by a simple allometric equation (Eq. 1) and an expanded allometric equation (Eq. 2):

and

$$
H=a D B H^{b} \quad \text { Eq. } 1
$$

$$
1 / H=1 / a D B H^{b}+1 / c \quad \text { Eq. } 2 \text {, }
$$

where $a\left(\mathrm{~cm} \mathrm{~cm}^{-b}\right)$ is the initial growth index, $b$ (dimensionless) is the ratio of relative growth rate of $H$ to that of $D B H$, and $c(\mathrm{~cm})$ is the asymptotic height (Ogawa et al. 1965, Yoda 1971, Kohyama and Hotta 1990). These parameters are the regression coefficients (Ogawa et al. 1965, Yoda 1971). Major axis regression was used to examine Eq. 1 (Sokal and Rohlf 1995). Eq. 2 has more parameters and fewer degrees of freedom (d.f.) compared to Eq. 1, so the sum of squares of residuals (RSS) of Eq. 2 is smaller than that of Eq. 1. Thus, nonlinearity of the allometric relationship on log-log plots was compared using analysis of variance; i.e., the significance of a decrease in the RSS was tested at the expense of reducing d.f. (Aiba and Kohyama 1997, Kimura and Simbolon 2002): $F=[(\mathrm{RSS} 1-\mathrm{RSS} 2) /$ (d.f. ${ }_{1}-$ d.f. $\left.\left._{2}\right)\right] /($ RSS2/d.f. 2$)$, where RSS1 and RSS2 are RSS in the regressions of Eq. 1 and Eq. 2, respectively, and d.f..$_{1}$ and d.f..$_{2}$ are d.f. of the regressions of Eq. $1(n-2)$ and Eq. 2 $(n-3)$, respectively. Additionally, regressions for both large and small individuals, based on $\mathrm{DBH}$, height, height under the crown and crown width, were calculated, utilising dominant trees below $40 \mathrm{~cm}$ in DBH outside the study plot. 
The OBIA method was adopted for the land cover classification, and implemented using commercially available software, 'Definiens Developer (formerly known as eCognition)' (Zhou et al., 2008). The first step in OBIA classification is segmentation of the image into image object primitives. In 'eCognition' technology; a new image object level is created, or morphology of an existing object is altered (Definiens, 2008). Subsequent steps of classification and segmentation algorithms were then applied to perform a hierarchical classification. In the first step of making the process tree, pixels in which brightness was equal to zero were classified into "back ground". Next, with the exception of the "back ground" class, objects were classified as "shadow" by determining their threshold value in the intensity band using "Feature View", a tool that allows for visualising a feature (image band or ratio of bands) and determining threshold values for classification. All other image objects were grouped into the "not shadow" class by using a membership function with inverted similarity to the class "shadow". The inverted similarity is a rule describing all image objects that are "not in the class shadow". All objects in the "not shadow" class were classified into either "ruin" by determining the ruin threshold values in the saturation and hue bands; or "vegetation" (essentially "not ruin") by using a membership function with inverted similarity to the class "ruin". At this point, only "vegetation" remained to be classified. In this last step, the crown projection map exported from ArcGIS was used to classify the crown trees into individual species. In this step, because the satellite imagery reflected the surface of the canopy layer, we employed only with zero OTC value. Statistical characteristics such as mean and standard deviation of each band (blue, green, red, NIR and Panchromatic layer), minimum and maximum of NIR, Brightness and NDVI were extracted from each polygon of crowns, and used as the independent variable in the next analysis. Species name was also extracted and used as the dependent variable.

The text file, which included both of the statistical characteristics as independent variables and the species name as dependent variables for each crown tree, was imported as an R data frame (R Development Core Team 2008). Classification and regression tree (CART) analysis was then performed. In the terminology of tree-structured methods, the entire data set is referred to as the root node of the tree. This root node is partitioned into subsets of the data that then comprise subsequent nodes. If a node is not subject to further partitioning, that node is called a terminal node. The decision rules that define whether a particular observation in the data set belongs to a particular node are called splits. The process of tree construction involves determining, for each node, which of a myriad of possible splits best explains the variability in the dependent variable in terms of the independent variables, and then deciding whether a node should be terminal or should be subject to further splits. The measure of variability used in making this decision is the deviance, a generalisation of the familiar residual sum of squares. If the dependent variable is categorical or ordinal, the resulting tree is called a classification tree; if the dependent variable is continuous, the tree is a regression tree.

\section{RESULTS AND DISCUSSION}

The total number of species $(\mathrm{DBH}>40 \mathrm{~cm}$ ) in the study plot was 45 . D. alatus showed the largest relative basal area $(30.6 \%)$, followed by L. calyculata $(27.3 \%)$, Irvingia malayana (6.2\%) and T. nudiflora (5.7\%) (Table 1). The frequency distribution for DBH for D. alatus, L. calyculata and T. nudiflora showed inverse J-shaped, unimodal and bimodal distributions (Fig. 1, 2). 
Table 1: Summary of all trees observed in the study plot. DBH: diameter at breast height; BA: basal area; RBA: relative BA

\begin{tabular}{|c|c|c|c|c|c|}
\hline Family & Scientific name & Max. DBH (cm) & $\mathrm{BA}\left(\mathrm{m}^{2} / \mathrm{ha}\right)$ & $\operatorname{RBA}(\%)$ & No. Stems (plot) \\
\hline Dipterocarpaceae & Dipterocarpus alatus A.DC. & 201.0 & 6.24 & 30.59 & 84 \\
\hline Lythraceae & Lagerstroemia calyculata Kurz & 230.0 & 5.57 & 27.31 & 85 \\
\hline Irvingiaceae & Irvingia malayana Oliver ex A.Benn. & 136.5 & 1.26 & 6.18 & 29 \\
\hline Datiscaceae & Tetrameles nudiflora $\mathrm{R} . \mathrm{Br}$. & 145.0 & 1.17 & 5.73 & 30 \\
\hline Ebenaceae & Diospyros decandra Lour. & 141.4 & 0.89 & 4.39 & 19 \\
\hline Moraceae & Artocarpus chama Buch.-Ham. & 124.2 & 0.56 & 2.72 & 16 \\
\hline Flacourtiaceae & Hydnocarpus anthelminthica Pierre \& Gagnep. & 120.5 & 0.51 & 2.49 & 22 \\
\hline Moraceae & Ficus altissima Blume & 225.0 & 0.51 & 2.49 & 2 \\
\hline Sapindaceae & Schleichera oleosa Merr. & 123.0 & 0.31 & 1.54 & 14 \\
\hline Alangiaceae & Alangium salviifolium (L.f.) Wangerin & 81.8 & 0.27 & 1.35 & 15 \\
\hline Ebenaceae & Diospyros curranii Merr. & 81.6 & 0.27 & 1.34 & 16 \\
\hline Moraceae & Streblus asper Lour. & 65.9 & 0.20 & 0.99 & 15 \\
\hline Apocynaceae & Alstonia scholaris (L.) R.Br. & 127.1 & 0.20 & 0.98 & 7 \\
\hline Loganiaceae & Strychnos nux-vomica L. & 82.4 & 0.19 & 0.94 & 8 \\
\hline Leguminosae-caesalpinioideae & Dialium cochinchinense Pierre & 85.7 & 0.19 & 0.92 & 8 \\
\hline Moraceae & Ficus callosa Willd. & 66.5 & 0.17 & 0.85 & 12 \\
\hline Moraceae & Ficus callophylla Blume & 110.0 & 0.17 & 0.84 & 4 \\
\hline Sterculiaceae & Pterospermum lanceifolium Roxb. \& DC. & 96.3 & 0.16 & 0.81 & 7 \\
\hline Meliaceae & Sandoricum koetjape Merr. & 93.5 & 0.15 & 0.73 & 9 \\
\hline Leguminosae-mimosoideae & Samanea saman Merr. & 82.6 & 0.12 & 0.58 & 5 \\
\hline Sapindaceae & Nephelium hypoleucum Kurz & 87.8 & 0.12 & 0.57 & 6 \\
\hline Sterculiaceae & Pterocymbium tinctorium Merr. & 81.5 & 0.11 & 0.54 & 7 \\
\hline Dipterocarpaceae & Anisoptera costata Pierre & 84.4 & 0.11 & 0.52 & 3 \\
\hline Lauraceae & Beilschmiedia roxburghiana Nees & 71.3 & 0.10 & 0.50 & 6 \\
\hline Meliaceae & Aglaia edulis Hiern & 57.3 & 0.10 & 0.47 & 8 \\
\hline Moraceae & Ficus drupacea Thunb. & 126.7 & 0.09 & 0.43 & 1 \\
\hline Combretaceae & Terminalia bialata Steud. & 62.8 & 0.08 & 0.41 & 6 \\
\hline Polygalaceae & Xanthophyllum glaucum Wall. & 67.5 & 0.07 & 0.33 & 4 \\
\hline Moraceae & Ficus tinctoria G.Forst. & 67.8 & 0.06 & 0.31 & 3 \\
\hline Meliaceae & Aphanamixis polystachya (Wall.) R.Parker & 60.4 & 0.06 & 0.31 & 5 \\
\hline Lauraceae & Dehaasia sp. & 60.4 & 0.05 & 0.26 & 3 \\
\hline Chrysobalanaceae & Parinari anamensis Hance & 65.8 & 0.04 & 0.20 & 2 \\
\hline Euphorbiaceae & Mallotus philippinensis Muell.Arg. & 53.8 & 0.04 & 0.19 & 3 \\
\hline Dipterocarpaceae & Hopea odorata Roxb. & 80.5 & 0.04 & 0.18 & 1 \\
\hline Euphorbiaceae & Antidesma bunius Spreng. & 47.7 & 0.04 & 0.17 & 3 \\
\hline Leguminosae-caesalpinioideae & Sindora siamensis Teijsm. ex Miq. & 74.0 & 0.03 & 0.15 & 1 \\
\hline Leguminosae-caesalpinioideae & Senna siamea (Lamarck) H.S.Irwin \& Barneby & 55.5 & 0.03 & 0.13 & 2 \\
\hline Meliaceae & Walsura robusta Roxb. & 43.4 & 0.02 & 0.10 & 2 \\
\hline Leguminosae-caesalpinioideae & Peltophorum dasyrachis Kurz ex Baker & 56.2 & 0.02 & 0.09 & 1 \\
\hline Myristicaceae & Knema globularia Warb. & 52.9 & 0.02 & 0.08 & 1 \\
\hline Leguminosae-papilionoideae & Dalbergia nigrescens Kurz & 52.4 & 0.02 & 0.07 & 1 \\
\hline Moraceae & Ficus annulata Blume & 43.8 & 0.01 & 0.05 & 1 \\
\hline Ebenaceae & Diospyros pilosanthera Blanco & 43.2 & 0.01 & 0.05 & 1 \\
\hline Rhizophoraceae & Carallia brachiata Merr. & 40.3 & 0.01 & 0.04 & 1 \\
\hline Moraceae & Ficus racemosa L. & 40.1 & 0.01 & 0.04 & 1 \\
\hline 21 families & 45 species & 230.0 & 20.38 & 100.00 & 480 \\
\hline
\end{tabular}


Fig. 1: Frequency distribution for all trees surveyed

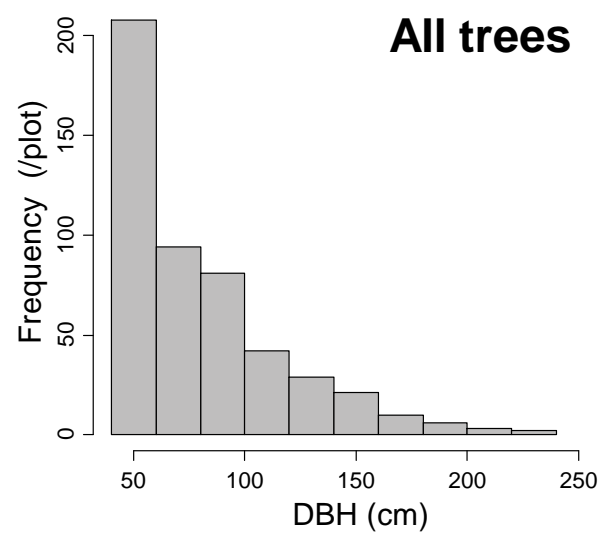

Fig. 2: Frequency distribution for the top three dominant tree species

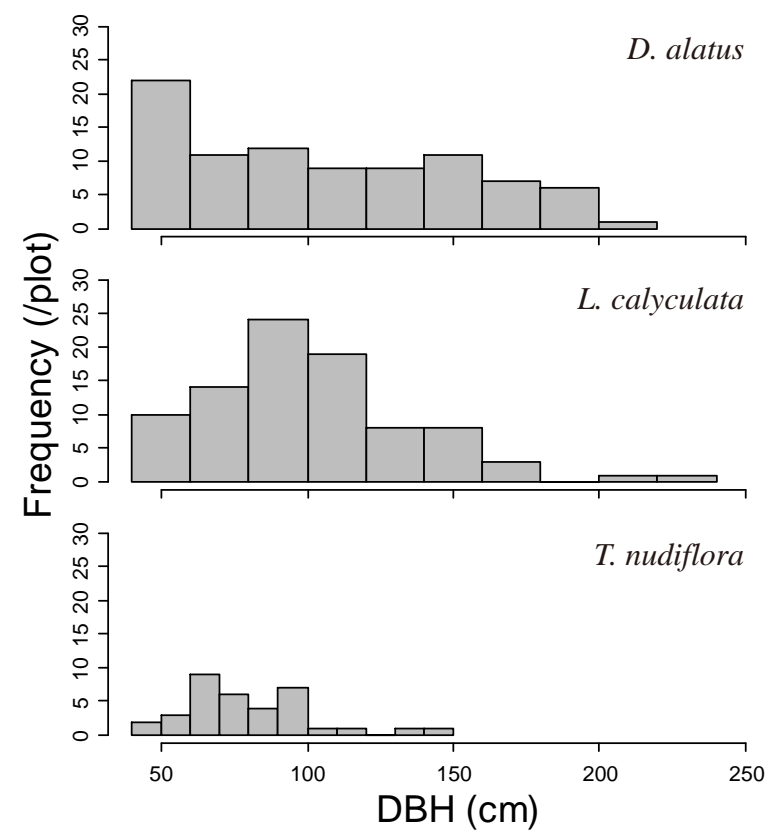

The inverse $\mathrm{J}$-shaped distribution of $D$. alatus suggests that the species is regenerating continuously, most likely due to favourable conditions for establishment and survival of seedlings and juveniles. On the other hand, unimodal and bimodal distributions of L. calyculata and T. nudiflora suggest that regeneration of these species had occurred simultaneously. In this forest, therefore, it is considered that D. alatus is a late-successional species while $L$. calyculata and T. nudiflora are early- and/or mid- successional species.

Eq. 2 resulted in a better fit of the allometric relationships between $H$ and $D B H$ of D. alatus, L. calyculata and T. nudiflora, while those between $H$ and crown width showed better fit in D. alatus, L. calyculata except for T. nudiflora (Table 2). 
Table 2: Results of analysis of variance comparing simple allometric equation and expanded allometric equation in each species.

DH: diameter and height relationship; DCW: diameter and crown width relationship; n.s.: not significant

\begin{tabular}{|c|c|c|c|c|c|c|c|}
\hline \multirow{2}{*}{ Spp. } & \multirow{2}{*}{$n$} & \multicolumn{2}{|c|}{ Simple allometry } & \multicolumn{3}{|c|}{ Expanded allometry } & \multirow{2}{*}{$F$} \\
\hline & & $a$ & $b$ & $a$ & $b$ & $c$ & \\
\hline $\mathrm{DH} /$ D. alatus & 197 & 0.32 & 0.64 & 0.91 & 1.06 & 59.52 & $157.75^{\text {*** }}$ \\
\hline $\mathrm{DH} /$ L. calyculata & 140 & 0.37 & 0.58 & 1.48 & 0.96 & 41.87 & $2.91^{\text {**** }}$ \\
\hline $\mathrm{DH} /$ T. nudiflora & 13 & 0.62 & 0.45 & 0.00 & 3.64 & 31.99 & $15.51^{* * *}$ \\
\hline DCW / D. alatus & 197 & -0.14 & 0.71 & 0.72 & 0.72 & 569043.56 & $4.70^{* * *}$ \\
\hline DCW / L. calyculata & 140 & -0.17 & 0.67 & 0.84 & 0.63 & 1019821.74 & $2.11^{* * * *}$ \\
\hline DCW / T. nudiflora & 13 & -0.82 & 1.04 & 0.35 & 0.93 & 56.83 & 1.63 n.s. \\
\hline
\end{tabular}

With respect to the results of the regression between $D B H$ and $H$, asymptotic height (i.e. parameter $c$ ) was greatest in D. alatus $(59.5 \mathrm{~m})$, followed by L. calyculata $(41.9 \mathrm{~m})$ and T. nudiflora $(32.0 \mathrm{~m})$. Parameter $b$ for D. alatus was similar to that for L. calyculata, although both differed from that of T. nudiflora (Fig. 3).

Fig. 3: Allometric relationships for the top three dominant tree species
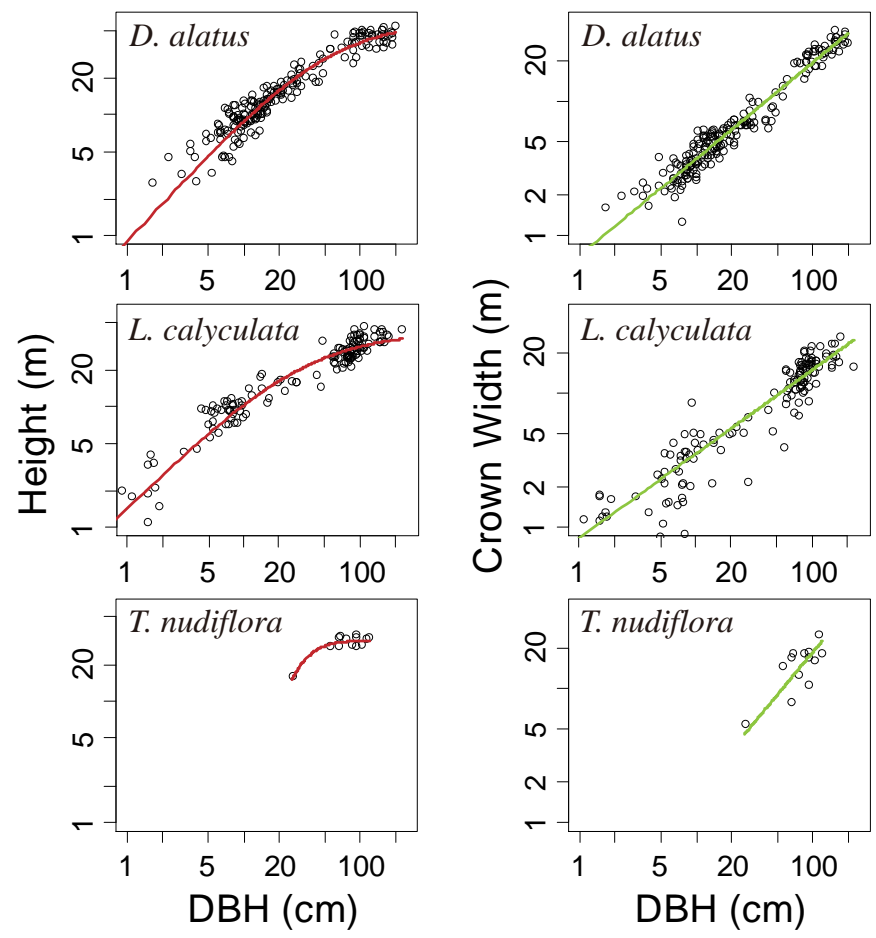
On the other hand, asymptotic crown width (i.e. parameter $c$ ) was difficult to estimate, although Eq. 2 showed a better fit than Eq. 1. When Hs and crown widths of stems that reached $150 \mathrm{~cm}$ in DBH were calculated using Eq. 2 with the estimated parameters for each species (Table 2), results of $\mathrm{H}$ were $45.0 \mathrm{~m}$ for D. alatus, $34.0 \mathrm{~m}$ for L. calyculata, and $32.0 \mathrm{~m}$ for T. nudiflora. In comparison, results of crown width were $26.6 \mathrm{~m}$ for D. alatus, $19.7 \mathrm{~m}$ for L. calyculata, and $37.0 \mathrm{~m}$ for T. nudiflora. These results suggest that stems in D. alatus are able to achieve greater height growth with the same DBH compared to stems of other species, while those in T. nudiflora are able to achieve greater growth in crown area. In the study site, large sized $D$. alatus, around $50 \mathrm{~m}$ in height, were distributed along the corridor leading to the temple, providing a spectacle subtropical forest landscape for visitors to enjoy. Visitors reaching the center of the monument on foot, on the other hand, are treated to a unique experience provided by the wide crown $T$. nudiflora with roots twisting around the temple walls. This dramatic change in scenery is made possible by species of tree that differ in their habitats, maximum attainable height and crown width.

From a spatial perspective, the top three dominant trees over $100 \mathrm{~cm}$ in DBH were segregated from each other. D. alatus, L. calyculata and T. nudiflora were concentrated respectively along the approach to the temple, near the centre of the complex, and on walls of the monument (Fig. 4). Negative spatial association-like distribution and differences in the parameters for asymptotic height resulted from differences in ecological traits among the tree dominant species, and is responsible for the dramatic shifts in scenery across the monument.

Fig. 4: Spatial distribution of stems for the top three dominant tree species

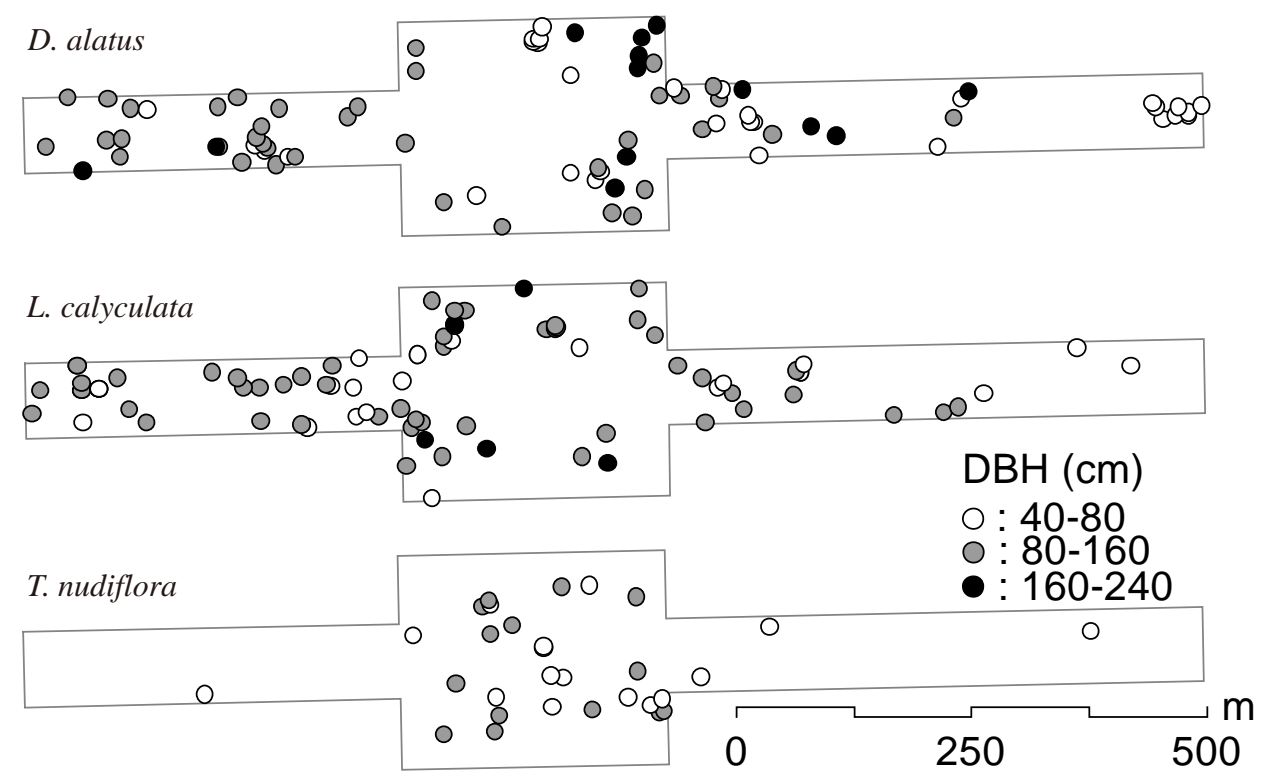

The number of species with OTC values greater than zero was 36, which accounts for $80 \%$ of the total 45 species observed in the study plot (Table 1, Fig. 5a). Mean and standard deviation of each band (blue, green, red, NIR and Panchromatic layer), minimum and maximum of NIR, Brightness and NDVI were extracted from polygons of OTC (Fig. 5b). 
Fig. 5: Crown projection map (a) and results of object based image analysis (b). Both maps overlaid onto QuickBird satellite imagery. OTC indicates the number of other tree canopies (OTC) over a target tree.

(a)

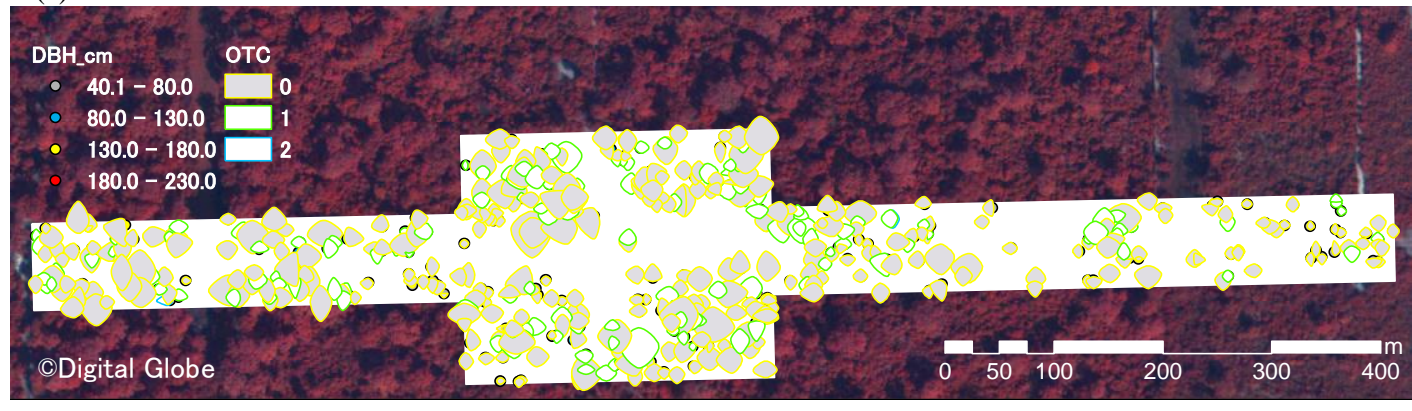

(b)

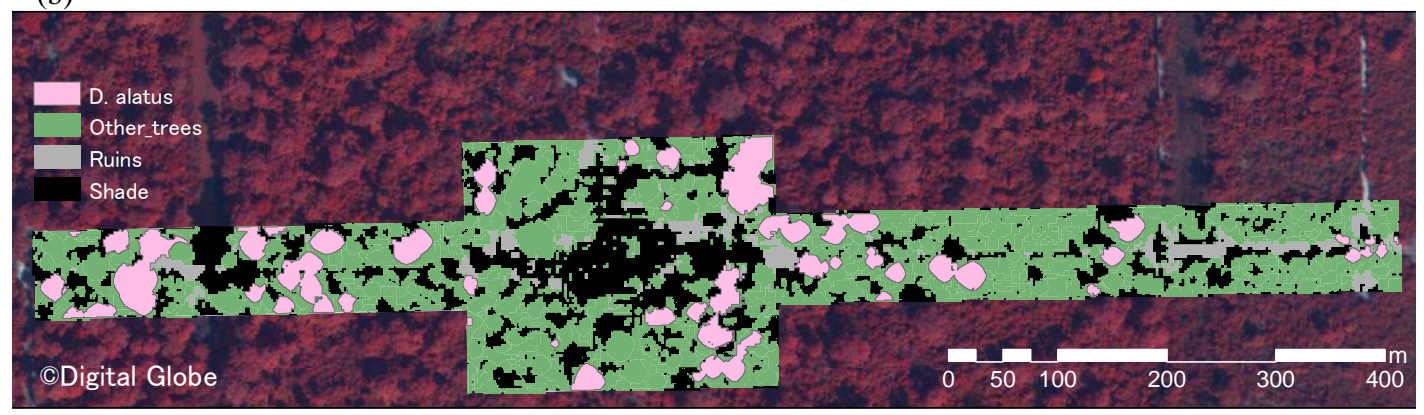

The best classification tree of the species in the extracted data set was shown in Figure 6 . By means of CART analysis, the tree can be seen to have three terminal nodes (Fig. 6).

Out of 14 potential predictors in the model specification, only two were selected by the cross-validation method. The total number of polygons of $D$. alatus in root node was 82 , of which those in the first partition and the second partition comprised 26 and 21 polygons, respectively (Fig. 6). 31.7\% of polygons in D. alatus showed values greater than, or equal to, 852 in maximum of NIR layer, while $25.6 \%$ of those showed less than 181.3 in mean digital number of panchromatic layer. By using these values, $57.3 \%$ of the D. alatus polygons were detected in the study plot, although other tree species also composed a canopy layer of this forest. For laborsaving identification and mapping of not only $D$. alatus but also other canopy trees, more information such as flowering phenology, as well as a reconstruction of the OBIA process tree, is needed in further research. 
Tomita M., Hirabuki Y., Araki Y., Tsukawaki S., Ly B. \& Hang P.: Potential of high-resolution satellite imagery for mapping distribution and evaluating ecological characteristics of tree species at the Angkor monument, Cambodia

Fig. 6: Result of decision tree using classification and regression tree (CART) analysis. Optimal pruning level was determined by using cross-validation method. Numerals separated by slash indicate frequency of polygons of each species. Frequency of polygons of D. alatus was represented by upper and fifth numeral from the left. Max and Mn5 indicates maximum of NIR layer and mean digital number of layer 5 (panchromatic layer), respectively. For more details, see Results and Discussion.

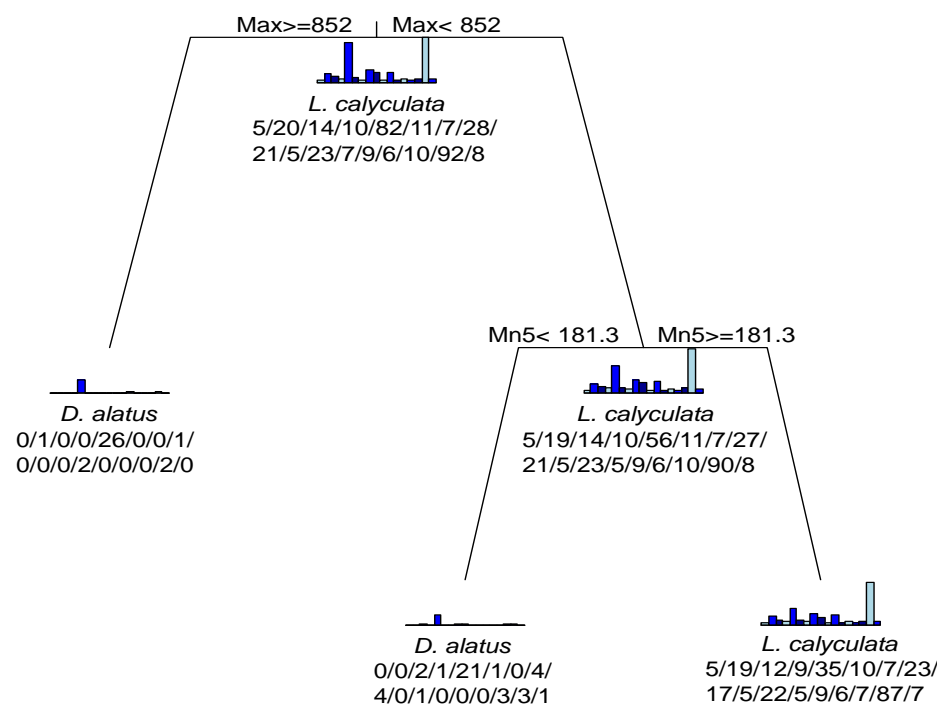

\section{ACKNOWLEDGEMENT}

We would like to thank the staff of the Authority for the Protection of the Site Management of Angkor and Region Siem Reap for local research support. This study was supported by a Grant-in-Aid for Scientific Research from the Ministry of Education, Culture, Sports, Science and Technology of Japan (19404003), and partly supported by the $3^{\text {rd }}$ phase research project for Sustainable Economic and Social Development Dependent on The Environment in Eastern Asia of The Tokyo University of Information Sciences; (Ministry of Education, Culture, Sports, Science and Technology (MEXT) support program S0801024).

\section{REFERENCES}

Aiba, S. \& Kohyama, T., (1997). Crown architecture and life-history traits of 14 tree species in a warm-temperate rain forest: Significance of spatial heterogeneity. $J$ Ecol, 85: 611-624.

Alexander, R. \& Millington, A. C., (2000). Vegetation Mapping. John Wiley \& Sons Ltd, Chichester.

Baatz, M. \& Schape, A., (2000). Multiresolution Segmentation - an optimization approach for high quality multi-scale image segmentation. In: Strobl J. \& Blaschke T. (eds.): Angewandte Geographische Informations Verarbeitung XII Wichmann-Verlag ( pp. 12-23).

Blaschke, T., (2010). ISPRS Journal of Photogrammetry and Remote Sensing Object based image analysis for remote sensing. ISPRS Journal of Photogrammetry and Remote Sensing, 65: 2-16. 
Blaschke, T., Lang, S., Lorup, E., Strobl, J. \& Zeil, P., (2000). Object-oriented image processing in an integrated GIS/remote sensing environment and perspectives for environmental applications. In: Cremers A. \& Greve K. (eds.): Environmental Information for Planning, Politics and the Public Metropolis Verlag (pp 555-570), Marburg.

Blaschke, T. \& Strobl J., (2001). What's wrong with pixels? Some recent development interfacing remote sensing and GIS, GeoBIT/GIS, 6: 12-17.

Definiens, (2008). Definiens Developer 7, User Guide. Definiens AG, Munchen.

Hirata, Y., Tsubota, Y. \& Sakai, A., (2009). Allometric models of DBH and crown area derived from QuickBird panchromatic data in Cryptomeria japonica and Chamaecyparis obtusa stands. International Journal of Remote Sensing, 30: 5071-5088.

Katoh, M., Gougeon, F.A. \& Leckie, D.G., (2009). Application of high-resolution airborne data using individual tree crowns in Japanese conifer plantations. Journal of Forest Research, 14: 10-19.

Kimura, M. \& Simbolon, H., (2002). Allometry and life history of a forest understory palm Pinanga coronata (Arecaceae) on Mount Halimun, west Java. Ecol. Res., 17: 323-338.

Kohyama T. AND Hotta M., 1990: Significance of allometry in tropical saplings. Functional Ecology, 4: 515-521.

Ogawa, H., Yoda, K., Ogino, K. \& Kira, T., (1965). Comparative ecological studies on three main types of forest vegetation in Thailand. II. Plant biomass. Nature and Life in Southeast Asia, 4: 49-80.

Palace, M., Keller, M., Asner, G.P., Hagen, S. \& Braswell, B., (2008). Amazon Forest Structure from IKONOS Satellite Data and the Automated Characterization of Forest Canopy Properties. Biotropica, 40: 141-150.

R Development Core Team, (2008). R: A language and environment for statistical computing. R Foundation for Statistical Computing, Vienna, Austria.

Sokal, R.R. \& Rohlf, F.J., (1995). Biometry third edition. W. H. Freedman and Company, New York.

Yoda, K., (1971). Ecology of forests. Tsukiji Press, Tokyo (in Japanese).

Zhao, Y., Tomita, M., Hara, K., Fujihara, M., Yang, Y. \& Da L., (2014). Effects of topography on status and changes in land-cover patterns, Chongqing City, China. Landscape Ecology and Engineering 10: 125-135.

Zhou, W., Troy, A. \& Grove, M., (2008). Object-based land cover classification and change analysis in the Baltimore metropolitan area using multitemporal high resolution remote sensing data. MDPI, Sensors, 8: 1613-1636. 